GOMES, A.R.A. et al. Estresse por calor na produção de frangos de corte. PUBVET, Londrina, V. 6, N. 34, Ed. 221, Art. 1469, 2012.

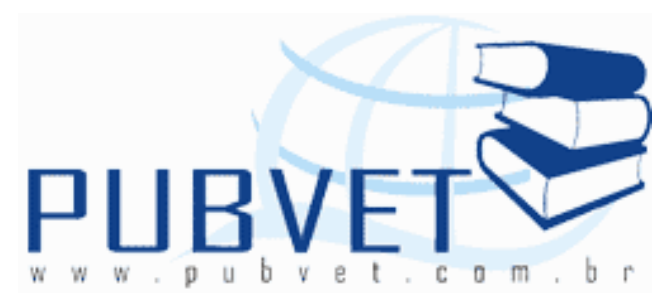

PUBVET, Publicações em Medicina Veterinária e Zootecnia.

\title{
Estresse por calor na produção de frangos de corte
}

Andréa Regina Abrantes Gomes ${ }^{1}$, Fernanda Heloisa Litz ${ }^{1}$, Hugo Ribeiro Morais ${ }^{1}$, Raquel Peres de Oliveira ${ }^{1}$, Mara Regina Bueno de Mattos Nascimento ${ }^{2}$

${ }^{1}$ Mestrandos em Ciências Veterinárias - Universidade Federal de Uberlândia

${ }^{2}$ Docente Faculdade de Medicina Veterinária - Universidade Federal de Uberlândia

\section{Resumo}

O aumento de produção que levou o Brasil a ocupar uma das maiores posições de produtor de frangos de corte do mundo se deve a intensificação de criação. Essa potencialização teve como base vários aspectos que foram cuidadosamente controlados, dentre eles o manejo (sistemas de criação, ambiência, sanidade entre outros). O objetivo desta revisão foi discutir sobre as principais consequências dos frangos de corte quando estes são submetidos ao estresse de calor. Foram abordadas variáveis referentes à fisiologia, comportamento, desempenho zootécnico e morfologia de órgãos de aves, de diferentes idades, submetidas a condições que ultrapassam sua zona de conforto térmico. Também, foi conceituado estresse, cíclico e constante, e sua influência no bem estar dos frangos e a atuação dos hormônios tireoidianos no organismo destes mediante as alterações térmicas na produção comercial.

Palavras-chave: avicultura, desempenho, hormônios tireoidianos. 
GOMES, A.R.A. et al. Estresse por calor na produção de frangos de corte. PUBVET, Londrina, V. 6, N. 34, Ed. 221, Art. 1469, 2012.

\title{
Heat stress on the production of broilers
}

\begin{abstract}
The increase in production that led Brazil to occupy a leading position as producer of broilers in the world is due to intensification of farming. This enhancement was based on several aspects that were carefully controlled, including the management (farming systems, environment, health among others). This review aims at discussing the main characteristics of broilers when they are subjected to thermal stress. Variables were discussed related to physiology, behavior, growth performance and organ morphology of birds of different ages, subjected to conditions beyond their thermal comfort zone. Also, it was conceptualized stress, cyclic and constant, and its influence on the welfare of chickens and the action of thyroid hormones in the body by means of thermal changes in commercial production.
\end{abstract}

Keywords: poultry, performance, thyroid hormones.

\section{Introdução}

Os progressos no campo da genética, manejo e sanidade animal transformaram a avicultura comercial brasileira numa potência em exportação de carne de frango. Esta atividade se desenvolveu num complexo setor econômico cujo objetivo é maximizar a produção com o menor custo. Neste contexto, diversos estudos vêm sendo realizados visando compreender melhor os fatores que interferem no desenvolvimento e desempenho de frangos de corte.

Entre os fatores ambientais que afetam a produtividade destas aves, os térmicos, temperatura e umidade do ar, são os mais impactantes, pois comprometem a manutenção de sua homeotermia. O sistema de produção avícola predominante no Brasil é de confinamento sendo este um agravante, pois acarreta num desbalanceamento do conforto térmico das aves, que reagem 
GOMES, A.R.A. et al. Estresse por calor na produção de frangos de corte. PUBVET, Londrina, V. 6, N. 34, Ed. 221, Art. 1469, 2012.

frente à essa mudança de temperatura, prejudicando desta forma, seus índices zootécnicos (SEVEGNANI et al., 2005).

Muitos avicultores, principalmente de regiões tropicais e subtropicais, têm enfrentado problemas causados por estes fatores durante os meses mais quentes do ano. À medida que a ave se desenvolve diminui sua resistência ao calor, o que tem feito aumentar o interesse por práticas nutricionais e ambientais, além de novas tecnologias que possam amenizar os efeitos estressores e promover o bem-estar a estes animais (MENEGALI et al., 2009).

No tocante ao desbalanceamento endócrino destas aves submetidas a estresse por calor, os hormônios tireoidianos têm sido considerados os mais importantes no controle dos processos metabólicos. Influenciam a eficiência alimentar, a síntese de catabolismo e anabolismo e a termogênese. Sabe-se, também, que estes exercem efeitos diferentes, dependendo do estágio de desenvolvimento e condições ambientais (DAHLKE et al., 2008).

Desta forma, objetivou-se neste estudo revisar as consequências fisiológicas e de desempenho de frangos de corte submetidos a estresse de calor.

\section{Revisão de literatura}

\section{Conceito de estresse}

Segundo Silva (2000), o estresse é caracterizado por todo tipo de agente externo que gera uma tensão ou resposta do ser vivo. Isto resulta em alterações comportamentais, fisiológicas e autônomas na tentativa de adaptação as mudanças ou promover melhor sobrevivência do organismo.

Existem diferentes tipos de agentes capazes de levar os animais a um estado caracterizado como de estresse (RODRIGUEZ, 2002; MARTINEZ, 2008). Estes agentes externos são denominados de estressores e são de naturezas diversas, como físicos (calor, frio, umidade), biológicos (estado nutricional, fome, 
GOMES, A.R.A. et al. Estresse por calor na produção de frangos de corte. PUBVET, Londrina, V. 6, N. 34, Ed. 221, Art. 1469, 2012.

sede), psicológicos (dor, ansiedade, medo) e mecânicos (contenção, instalações), além dos considerados de origem social como a hierarquia ou dominância de indivíduos sobre outros da mesma espécie.

\subsection{Definição de estresse térmico}

Silva (2000) cita que o estresse térmico é a força exercida pelos componentes do ambiente térmico sobre um organismo que resulta em reações fisiológicas proporcionais à intensidade de força aplicada e à capacidade do organismo em compensar tais alterações. Se o ambiente apresentar temperaturas elevadas ou inferiores das quais o indivíduo opera melhor, então há uma condição de estresse térmico. Desta forma, quando um animal é submetido a um determinado ambiente, as trocas térmicas que realiza com o meio dependem da situação em que ambos se encontram.

\section{Conforto térmico na avicultura}

A ave por ser um animal homeotérmico, seu organismo é mantido a uma temperatura interna constante pelo aparelho termorregulador que comanda a redução ou o aumento das perdas de calor pelo organismo. Desta forma, para a manutenção do conforto térmico, há necessidade de equilíbrio nos sistemas internos de aquecimento e refrigeração (SILVA, 2000).

De acordo com Furlan (2006), a zona de conforto térmico ou termoneutra pode ser indicada como sendo a faixa de temperatura ambiente na qual a taxa metabólica é mínima e a homeotermia é mantida com menor gasto energético. Esta zona apresenta os limites de temperaturas nos quais o indivíduo expressa todo seu potencial genético para a produção e reprodução (CURTO et al., 2007; FERREIRA, 2005). No entanto, condições de conforto térmico são dificilmente 
GOMES, A.R.A. et al. Estresse por calor na produção de frangos de corte. PUBVET, Londrina, V. 6, N. 34, Ed. 221, Art. 1469, 2012.

obtidas em países cujo clima predominante é tropical, como é o caso do Brasil, sendo que durante quase o ano todo, a temperatura ambiente, a intensidade de radiação solar e umidade do ar são muito elevados (MARCHINI et al., 2007; MEDEIROS et al., 2005).

Tais variáveis ambientais segundo Marchini et al. (2007) e Sevegnani et al. (2005) são desfavoráveis à criação de frangos de corte nessas regiões, pois estes são muito suscetíveis à elevação de temperatura ambiente. Seu desempenho zootécnico é prejudicado, resultando num crescimento abaixo do esperado e peso à idade de abate inferior ao comparado a animais criados em zonas com maior conforto térmico.

Um ambiente é considerado confortável para aves adultas quando apresenta temperaturas de 16 a $23^{\circ} \mathrm{C}$ e umidade relativa do ar de 50 a $70 \%$; porém, quando a temperatura ambiente se eleva acima da zona de termoneutralidade, a ave é submetida ao estresse térmico (TINÔCO, 1998). De acordo com Dionello et al. (2002), o máximo desenvolvimento das aves adultas é alcançado em temperaturas entre 18 e $20^{\circ} \mathrm{C}$ e quando excede $38^{\circ} \mathrm{C}$, ocorrem elevadas mortalidades. A morte ocorre rapidamente por exaustão, principalmente em aves mais pesadas (BROSSI et al., 2009).

Desta forma, estas oscilações bruscas de temperatura ambiente causam efeitos negativos sobre a produção de frangos de corte. Altas temperaturas resultam num baixo consumo de alimento, consequentemente, numa baixa produtividade. Já temperaturas baixas, o consumo de alimento é maior, porém boa parte da energia ingerida é direcionada para produção de calor interno, resultando numa pior conversão alimentar (FERREIRA, 2005; MARTINEZ, 2008). 
GOMES, A.R.A. et al. Estresse por calor na produção de frangos de corte. PUBVET, Londrina, V. 6, N. 34, Ed. 221, Art. 1469, 2012.

\section{Termorregulação}

A temperatura corporal dos animais homeotérmicos depende da energia térmica estocada por unidade de massa corporal sendo que essa pode ser aumentada ou diminuída pelos processos de termogênese e termólise, respectivamente (SILVA, 2000). Quando a temperatura ambiente encontra-se abaixo da temperatura de conforto térmico, os mamíferos e as aves precisam aumentar a produção de calor corporal pela termogênese, ao passo que, quando a temperatura ambiente encontra-se acima desta zona aumenta a termólise, situação na qual o animal precisa perder calor para o ambiente.

Ambos os casos utilizam a energia de mantença para gerar ou dissipar calor, diminuindo, desta maneira, a energia que seria utilizada para a produção e/ou reprodução (NAZARENO et al., 2011). Tanto na termogênese como a termólise envolvem três mecanismos. Comportamentais - quando os animais alteram seu comportamento de modo a aumentar ou diminuir a exposição térmica oriunda do ambiente. Autônomos - quando envolve o controle de várias funções orgânicas como: fluxo sanguíneo, variação da posição de penas entre outras; Adaptativas - as quais abrangem alterações a médio ou longo prazo de certas características, tais como: alterações dos níveis hormonais, pigmentação da epiderme entre outros (SILVA, 2000).

\subsection{Mecanismos de produção de calor}

Os mamíferos e aves são considerados animais homeotérmicos os quais apresentam a capacidade de manter a temperatura corpórea constante mesmo em situações de alteração na temperatura ambiente. Tais animais precisam manter um alto índice metabólico para produzirem o calor necessário a 
GOMES, A.R.A. et al. Estresse por calor na produção de frangos de corte. PUBVET, Londrina, V. 6, N. 34, Ed. 221, Art. 1469, 2012.

manutenção de sua temperatura corporal. Isto requer uma alta captação de energia e, portanto, uma busca constante por alimento (CUNNINGHAM, 2008).

A termogênese, em sua maior parte se origina do metabolismo alimentar. Os glicídios, lipídios e proteínas são usados pelas células para sintetizar grandes quantidades de ATP, fonte de energia para as funções celulares. Este processo pode ser afetado pela atividade muscular, ritmo metabólico, elevação da atividade simpática, atividade hormonal e calor adquirido de fontes exógenas (BIANCO, 2000).

Do ponto de vista fisiológico, admite-se que a produção de calor nos animais possa ser dividida em duas categorias: termogênese obrigatória e facultativa (BIANCO, 2000). A primeira é designada como fonte de calor originada das reações ligadas ao metabolismo basal, é, também, o resultado das reações que envolvem a síntese e a hidrólise do ATP associado em grande parte a ciclos metabólicos e relaxamento muscular derivado do trabalho muscular basal. Já a termogênese facultativa, por sua vez, é todo o calor produzido além do metabolismo basal associado à contração muscular durante atividades diárias mínimas, podendo também ser derivada de processos involuntários, tais como o tremor muscular ou tiritação (LUTAIF; GONTIJO, 2009).

Seja termogênese obrigatória ou facultativa, o controle do mecanismo é feito via endócrina, a partir de estímulos externos os quais são transmitidos ao centro hipotalâmico. O sinal procedente deste centro estimula a hipófise anterior a liberar hormônio tireotrópico (TSH) que, subsequentemente, induzirá a glândula tireóide a produzir $\mathrm{T}_{3}$ e $\mathrm{T}_{4}$. Simultaneamente, a hipófise produz estímulos sobre a glândula adrenal ao liberar o hormônio adrenocorticotrópico (ACTH). Todos estes hormônios agem sobre os tecidos, gerando calor metabólico (SILVA, 2000). 
GOMES, A.R.A. et al. Estresse por calor na produção de frangos de corte. PUBVET, Londrina, V. 6, N. 34, Ed. 221, Art. 1469, 2012.

\subsection{Mecanismos de transferência de energia térmica}

Os animais, segundo Cunningham (2008), possuem mecanismos básicos para perder ou absorver calor para o ambiente. Estes mecanismos podem ser divididos em duas categorias: não evaporativos ou sensíveis e evaporativos ou latentes. Os meios não-evaporativos incluem condução, convecção e radiação e requerem um diferencial de temperatura entre o animal e o meio ambiente. Os evaporativos ou latentes incluem a perda de calor por evaporação de água por respiração e sudação (GUYTON ; HALL, 1997).

A condução térmica, por sua vez, consiste na transferência de energia entre as partículas formadoras do corpo, sem que ocorra o transporte de matéria durante o processo. Esse fluxo passa das moléculas de alta energia para as de baixa, ou seja, de zona de alta temperatura para outra inferior, sendo necessário um contato direto entre as moléculas dos corpos envolvidos (SILVA, 2000).

A irradiação segundo Cunningham (2008) e Silva (2000), pode ser definida como a transferência de energia de um corpo para outro por ondas eletromagnéticas. No caso dos animais, estes recebem calor a partir do ambiente quando a temperatura, onde eles se encontram, excede a do corpo ao serem expostos a fontes que irradiam calor.

Desta forma, em climas tropicais, a temperatura do ar encontra-se frequentemente próxima da corporal ou a excede; além disso, a temperatura radiante média do ambiente tende a ser muito mais elevada que a atmosférica. Consequentemente, a termólise por convecção e radiação é dificultada ou inibida. Em adição, se a região for também úmida, a perda de calor por evaporação será prejudicada, proporcionando um elevado estresse pelo calor. Quando a temperatura ambiente sobe acima de $29^{\circ} \mathrm{C}$, para aves adultas, a via de perda de calor mais eficiente é por meios evaporativos (BIANCO, 2000). 
GOMES, A.R.A. et al. Estresse por calor na produção de frangos de corte. PUBVET, Londrina, V. 6, N. 34, Ed. 221, Art. 1469, 2012.

\section{Fisiologia do estresse pelo calor}

Como o funcionamento do corpo é resultado de processos químicos e físicos sensíveis a alterações na temperatura, os animais utilizam várias estratégias para regular a temperatura de seus tecidos (GUYTON, HALL, 1997). De acordo com Cunningham (2008), para todos os mamíferos e aves, existe uma temperatura ambiente na qual a temperatura corporal pode ser mantida numa faixa normal, principalmente por mecanismos vaso-motores. Esta zona de neutralidade térmica varia com a taxa metabólica e a quantidade de isolamento.

Segundo Medeiros et al. (2005) e Welker et al. (2008), o aumento na temperatura corporal das aves é resultado direto de um desbalanceamento entre as perdas de calor por meios evaporativos e sensíveis e a produção de calor. Tal condição é agravada devido ao fato das aves não possuírem glândulas sudoríparas e, logo, não têm a capacidade de transpirar. Desta forma, estes animais liberam o excesso de calor pela respiração e pelas superfícies desprovidas de penas como cristas, barbelas e outras áreas.

Entre as respostas fisiológicas compensatórias das aves, quando expostas ao calor, destaca-se a vasodilatação periférica. Este mecanismo resulta num aumento do fluxo sanguíneo para as regiões desprovidas de penas e extremidades com intuito de aumentar a perda de calor não evaporativo. Esta perda não evaporativa também pode ocorrer pelo aumento da micção, se estiver associada ao elevado consumo de água fria (MARTINEZ, 2008).

Oliveira et al. (2000) em seus estudos demonstraram que durante períodos de estresse térmico, as extremidades das aves que não possuem penas são vasodilatadas. Curto et al. (2007) citaram que área total de superfície destas regiões corresponde a $10 \%$ da superfície total do corpo o que contribui para a perda de calor sensível. O ofego, por sua vez, se torna eficiente apenas quando a umidade do ar se encontra em níveis relativamente baixos. 
GOMES, A.R.A. et al. Estresse por calor na produção de frangos de corte. PUBVET, Londrina, V. 6, N. 34, Ed. 221, Art. 1469, 2012.

As aves, conforme Curto et al. (2007), tentam compensar sua reduzida habilidade de dissipar calor latente, em condições de estresse térmico, ativando os processos fisiológicos responsáveis pela dissipação de calor para o ambiente externo. Elas adotam um comportamento diferenciado, abrindo suas asas e mantendo-as afastadas do corpo, aumentando sua área de superfície corporal, além de diminuírem sua atividade física, facilitando perdas por convecção.

De acordo com Moura (2001), quando a temperatura ambiente se aproxima da temperatura corporal das aves, $41^{\circ} \mathrm{C}$, nesse ponto a dissipação de calor por radiação, condução e convecção já diminuíram. Antes disto, o principal mecanismo de perda de calor é a evaporação de água pelo trato respiratório. Quanto maior for a pressão de vapor do ambiente, maior é a dificuldade de liberação de calor por meios evaporativos. O aumento dos movimentos respiratórios somente é eficiente quando a umidade do ar se encontra em níveis relativamente menores que $70 \%$. Quando as trocas evaporativas já não são mais efetivas na perda de calor, as aves entram em prostação podendo chegar à morte.

Este aumento da frequência respiratória resulta em perdas excessivas de dióxido de carbono $\left(\mathrm{CO}_{2}\right)$. Assim, a pressão parcial de $\mathrm{CO}_{2}\left(\mathrm{pCO}_{2}\right)$ diminui, levando a redução nas concentrações de acido carbônico $\left(\mathrm{H}_{2} \mathrm{CO}_{3}\right)$ e dos íons de hidrogênio $\left(\mathrm{H}^{+}\right)$(MARCHINI et al., 2007; NAZARENO et al., 2009). Segundo os mesmos autores, em resposta compensatória, os rins aumentam a excreção de $\mathrm{HCO}^{3-}$ e reduzem a perda de $\mathrm{H}^{+}$na tentativa de manter o equilíbrio ácido-base da ave. Tal alteração é denominada alcalose respiratória.

\section{Estresse por calor de acordo com a faixa etária das aves}

De acordo com Marchini et al. (2007) e Mazzi et al. (2002) a temperatura corporal aumenta conforme a idade do frango, independentemente da 
GOMES, A.R.A. et al. Estresse por calor na produção de frangos de corte. PUBVET, Londrina, V. 6, N. 34, Ed. 221, Art. 1469, 2012.

temperatura ambiente, e a frequência respiratória reduz com a idade para as aves em termoneutralidade. No tocante a frangos de corte modernos, estes atingem o desenvolvimento de sua habilidade termorreguladora entre 10 a 15 dias de vida. Assim sendo, os recém nascidos dependem de uma fonte de aquecimento para que possam manter sua temperatura corporal em torno de $40^{\circ} \mathrm{C}$ (FERREIRA, 2005). Aves adultas segundo observações de Martinez (2008) e Welker et al. (2008), apresentam temperatura corporal oscilado entre 41 e $42^{\circ} \mathrm{C}$, porém variam conforme a espécie, idade, umidade relativa, sexo, peso corporal, atividade física e consumo de alimento.

Segundo Oliveira (2006), as aves não resistem, por longos períodos, a temperaturas de $5^{\circ} \mathrm{C}$ acima da corporal por causa da sua relação superfície/massa ser maior. Em contra partida, resistem a temperaturas baixas podendo ser a $20^{\circ} \mathrm{C}$ abaixo de sua temperatura normal interna, evidenciando sua capacidade de isolamento ao frio. Desta forma fica implícito que a zona de conforto térmico é variável, sendo assim, pinto de 1 a 7 dias de vida situam-se numa zona termoneutra entre 31 a $33^{\circ} \mathrm{C}$ diminuindo para 21 a $23^{\circ} \mathrm{C}$ na idade de 35 a 42 dias, considerando umidade relativa do ar entre 65 a 70\% (OLIVEIRA et al., 2006).

\section{Desempenho produtivo sob estresse pelo calor em aves}

O termo "estresse por calor" pode ser subdividido em agudo ou crônico, entre outras palavras, cíclico ou constante. O estresse cíclico refere-se a períodos repetidos de grande elevação da temperatura ambiente que podem chegar até 12 horas seguidas (LAGANÁ et al., 2007), ao passo que, o estresse considerado constante é a elevação da temperatura durante um dia ou mais. O Brasil é um exemplo de país cuja temperatura ambiental predominante sofre elevações constantes por longos períodos, enquanto em regiões de clima temperado como 
GOMES, A.R.A. et al. Estresse por calor na produção de frangos de corte. PUBVET, Londrina, V. 6, N. 34, Ed. 221, Art. 1469, 2012.

nos Estados Unidos há curtos períodos de elevação da temperatura (MARTINEZ, 2008).

A maior parte dos experimentos envolvendo calor é conduzida em situações de exposição ao calor de forma crônica. Os resultados mostram redução do consumo alimentar e da taxa de crescimento e piora da conversão alimentar. Souza (2008) concluiu que a exposição crônica ao calor reduziu o ganho de peso em 25 a 35\% e a ingestão de alimento em 15 a 20\%, resultando em uma significativa piora na conversão alimentar a $32^{\circ} \mathrm{C}(10$ a $30 \%)$ em relação à $22^{\circ} \mathrm{C}$. Entretanto, nas condições ambientais naturais, a exposição ao calor ocorre de forma cíclica. Assim, existe uma variação na temperatura ao longo do dia, havendo um período de temperaturas mais amenas e outro com temperaturas mais elevadas, que afeta o desempenho zootécnico das aves.

Ainda Souza (2008) estudou o efeito de temperaturas cíclicas no desempenho de frangos de corte em fase de crescimento ( 3 a 8 semanas). Os resultados que obteve mostraram que o ganho de peso e consumo de ração foram maiores quando a temperatura foi constante $\left(23,9^{\circ} \mathrm{C}\right)$ ou com amplitude térmica de $5,6^{\circ} \mathrm{C}\left(12\right.$ horas a $18,3^{\circ} \mathrm{C}$ e 12 horas a $\left.23,9^{\circ} \mathrm{C}\right)$, desta forma, concluiu que a taxa de crescimento declinou com o aumento da amplitude das temperaturas.

A capacidade das aves em suportar o calor é inversamente proporcional ao teor de umidade do ar. Quanto maior esta, a ave terá mais dificuldade em remover calor interno pelas vias aéreas, levando a um aumento da frequência respiratória. O processo que a ave realiza para manter sua homeotermia promove alterações fisiológicas que podem comprometer seu desempenho (OLIVEIRA et al., 2006).

Fabricio (1994) relatou que o estresse por calor é responsável por grandes perdas no rendimento dos lotes de frangos, gerando um aumento de mortalidade e piora na conversão alimentar, além de diminuição do peso corporal, 
GOMES, A.R.A. et al. Estresse por calor na produção de frangos de corte. PUBVET, Londrina, V. 6, N. 34, Ed. 221, Art. 1469, 2012.

principalmente quando as condições estressantes ocorrem na fase final, próximo ao abate.

Quando expostas ao estresse as aves respondem por meio de diminuição da ingestão de alimentos, reduzindo assim a ingestão de nutrientes com efeito direto sobre a resposta produtiva (MARTINEZ, 2008). A diminuição do consumo de ração observado em frangos de corte mantidos em estresse de calor é uma das maneiras de tentar reduzir a produção de calor metabólico. Essa redução do consumo de ração é acompanhada de piora no ganho de peso e na conversão alimentar, conforme constatado por Baziz et al. (1996).

Além do desempenho, a temperatura ambiente modifica a retenção de energia, proteína e gordura no corpo animal e causa diversas mudanças adaptativas fisiológicas. Uma dessas alterações é a modificação no tamanho dos órgãos, o que também contribui para influenciar a exigência nutricional das aves, já que o gasto de energia pelos tecidos metabolicamente ativos, como fígado, intestino e rins são maiores que aquele associado à carcaça (BALDWIN et al., 1980).

\section{Efeito do estresse de calor sobre rendimento de órgãos}

O peso relativo do coração dos frangos quando estudados por Plavnik \& Hurwitz (1985) foram menores nos tratamentos com restrição alimentar como também àqueles submetidos ao estresse por calor quando comparado com outros mantidos em ambiente termoneutro. Para os animais submetidos à estresse por calor Plavnik \& Yahav (1998) encontraram uma redução do peso do fígado e atribuíram tal fato à redução na atividade metabólica.

Ribeiro et al. (2001), observaram que após período de estresse pelo calor, devido ao fato dos nutrientes terem sido dirigidos preferencialmente para outros tecidos, não há ganho compensatório para o intestino, moela, coração e fígado. 
GOMES, A.R.A. et al. Estresse por calor na produção de frangos de corte. PUBVET, Londrina, V. 6, N. 34, Ed. 221, Art. 1469, 2012.

Encontraram também um peso absoluto do coração menor para as aves submetidas ao estresse por calor. Oliveira Neto et al. (2000), encontraram rendimento de fígado de $12 \%$ menor nas aves submetidas à estresse pelo calor quando comparadas à aves de ambiente termoneutro. Os autores afirmaram que a redução observada no peso dos órgãos de aves que foram expostas à altas temperaturas deve-se a um ajuste fisiológico, como tentativa de redução da produção de calor pelo corpo.

O peso da carcaça, o rendimento dos cortes nobres, a deposição de gordura abdominal (BAZIZ et al., 1996) e o peso das penas (GERAERT et al., 1996) como também o peso dos órgãos abdominais de frangos de corte podem ser reduzidos pela alta temperatura ambiente.

\section{Hormônios tireoidianos e estresse térmico em aves}

De acordo com Golzález \& Silva (2006), a glândula tireóide sintetiza três hormônios, a 3, 3', 5'- triiodotironina $\left(T_{3}\right)$, a 3, 5, 3', 5' - tetraiodotironina ou tiroxina $\left(T_{4}\right)$ e calcitocina. Os dois primeiros estão relacionados com a regulação do metabolismo de glicose, lipídeos e proteínas bem como termorregulação de mamíferos e aves, aumentando o metabolismo basal dos mesmos.

De acordo com Silva (2000) os hormônios tireoidianos $T_{3}$ e $T_{4}$ têm sido considerados os mais importantes no controle dos processos metabólicos das aves, influenciando o crescimento das diferentes estruturas corporais. Segundo o mesmo autor, além de aumentar a eficiência alimentar, o consumo de oxigênio, a síntese e metabolismo de proteínas, carboidratos e lipídios, a termogênese e a composição corporal.

Segundo Dahlke et al. (2005a), o aumento nos níveis destes hormônios pode acelerar os diversos mecanismos de controle do crescimento e o desenvolvimento de um grande número de órgãos, como o cérebro e o fígado, e a 
GOMES, A.R.A. et al. Estresse por calor na produção de frangos de corte. PUBVET, Londrina, V. 6, N. 34, Ed. 221, Art. 1469, 2012.

estrutura esquelética. Estimulam também o crescimento das cartilagens, aumentando seu peso. Esta variação hormonal também aumenta a síntese protéica, auxiliando a incorporação de aminoácidos sulfurados.

De acordo com Golzález e Silva (2006), os hormônios tireoidianos afetam o metabolismo dos carboidratos de vários modos, melhorando a absorção de glicose pelo lúmen intestinal e a promoção da movimentação desta nos tecidos adiposo e muscular. Ademais, tais hormônios promovem a absorção de glicose pelas células mediadas pela insulina. Cunningham (2008) e Guyton e Hall (1997), também afirmaram que a formação de glicogênio é facilitada por pequenas quantidades destes hormônios, entretanto, a glicogenólise ocorre com dosagens maiores.

No caso do metabolismo de lipídios, Cunningham (2008) enfatizou a importante influência dos hormônios tireoidianos na lipólise. Em se tratando de mobilização de lipídios, Guyton e Hall (1997) citaram que os hormônios tireoidianos aumentam a mobilização de ácidos graxos livres no plasma além de acelerar a oxidação destes pelas células. Outro efeito destes hormônios é a tendência de reduzir os níveis plasmáticos de colesterol, o que parece envolver uma maior absorção celular de lipoproteínas de baixa densidade (LDLs) com as moléculas de colesterol associadas. Outro mecanismo pelo qual os homônimos $T_{3}$ e $T_{4}$ diminuem a concentração de colesterol plasmático é pelo fato destes aumentarem a taxa de secreção do colesterol pela bile com sua consequente perda nas fezes (GUYTON; HALL, 1997).

Como os hormônios tireoidianos aumentam as quantidades de muitas enzimas e como algumas vitaminas trabalham em associação a coenzimas, tais hormônios provocam um consumo maior de vitaminas (GUYTON; HALL, 1997). Desta forma, segundo Cunningham (2008), uma deficiência relativa de vitaminas pode ocorrer quando é secretado um excesso de $T_{3}$ e $T_{4}$. Portanto, há necessidade em alguns casos de suplementação vitamínica na ração. 
GOMES, A.R.A. et al. Estresse por calor na produção de frangos de corte. PUBVET, Londrina, V. 6, N. 34, Ed. 221, Art. 1469, 2012.

A atividade tireoidiana, segundo Golzález e Silva (2006), está intimamente relacionada na aclimatação dos animais homeotérmicos. Estes autores citam que Quando os animais sofrem por estresse de frio, é observado um incremento na interconverção de $\mathrm{T}_{4}$ (inativa) em $\mathrm{T}_{3}$ (ativa) nos tecidos periféricos, o que permite dispor com maior rapidez do hormônio em sua forma ativa para compensar os requerimentos calóricos, ao passo que, sob estresse por calor há uma menor ativação destes hormônios devido ao baixo requerimento energético.

Dahlke et al. (2005b) verificaram uma redução na concentração plasmática de $T_{4}$, aos 21 dias, nas aves criadas em ambiente frio e um aumento nas concentrações deste hormônio em alta temperatura. Os autores concluem que esta diminuição nas concentrações de $\mathrm{T}_{4}$ ocorreu devido a alta conversão deste em sua forma ativa $\left(T_{3}\right)$. No entanto, aos 35 dias de idade houve uma redução nos valores de $T_{4}$, quando expostos ao calor, sem haver diferença para esta variável, entre as aves criadas em ambiente frio e termoneutro.

Dahlke et al. (2005a) e (2008), identificaram um aumento significativo nas concentrações plasmáticas de $T_{3}$, aos 21,35 e 42 dias de idade, nas aves criadas em temperatura fria, e uma redução quando criadas em clima quente. Ainda os autores supracitados afirmaram que as células do folículo da pena crescem sob ação direta do hormônio $T_{3}$, o qual em altas concentrações provoca invaginação da epiderme para a derme subjacente.

Os hormônios tireoidianos também exercem influência no desenvolvimento embrionário (DAHLKE et al., 2008). Ao analisar temperatura de incubação, os autores verificaram que quando esta temperatura for menor que a recomendada, a partir do 170 dia, há uma diminuição significativa nos valores plasmáticos de $T_{3}$ e $T_{4}$ no período pré-natal.

A atividade da tireóide parece tornar-se menor com o aumento da temperatura ambiente e as aves apresentam maior tolerância ao calor quando há diminuição nos valores circulantes destes hormônios (DAHLKE et al., 2008). 
GOMES, A.R.A. et al. Estresse por calor na produção de frangos de corte. PUBVET, Londrina, V. 6, N. 34, Ed. 221, Art. 1469, 2012.

Sendo assim, a temperatura ambiente inadequada altera a constituição hormonal de $\mathrm{T}_{3}$ e $\mathrm{T}_{4}$.

\section{Conclusão}

Pode-se concluir com esta revisão que o estresse por calor em frangos de corte gera alterações comportamentais e fisiológicas o que, independemente da idade e sexo das aves, resulta na piora dos índices zootécnicos, que é caracterizado principalmente por um menor consumo de ração. A atividade tireoidiana está intimamente relacionada com a aclimação dos frangos, podendo aumentar a secreção de $T_{3}$ e $T_{4}$ sob temperaturas baixas e diminuir as concentrações plasmáticas destes hormônios sob estresse por calor.

\section{Referências}

BALDWIN, R.L.; SMITH, N.E.; TAYLOR, J.; SHARP, M. Manipulating metabolic parameters to improve growth rate and milk secretion. Journal of Animal Science , Albany, v.51, p.14161428, 1980.

BAZIZ, H.A.; GERAERT, P.A.; GUILLAUMIN, S. Chronic heat exposure enhances fat deposition and modifies muscle and at partition in broiler carcasses. Poultry Science, Ithaca, v.75, p. 505-513, Abril, 1996.

BIANCO, A. C. Hormônios tireóideos, UCPs e termogênese. Arquivo Brasileiro de

Endocrinologia Metababologia [online], São Paulo, v.44, n.4, p. 281-289, 2000. Disponível em: < http://www.scielo.br/pdf/abem/v44n4/10938.pdf > Acesso em: 18 Jun. 2012.

BROSSI, C.; CONTRERAS-CASTILLO, C.J.; AMAZONAS, E.A.; MENTEN, J.F.M.; Estresse térmico durante o pré-abate em frangos de corte, Ciência Rural, Santa Maria, v.39, n.4, Julho, 2009.

CUNNINGHAM, J.G.; KLEIN, B.G. Tratado de fisiologia veterinária. In:

Termoregulação. Tradução de Aldacilene Souza da Silva; Rio de Janeiro: Elsevier, p. 648-656, 2008.

CURTO, F.P.F.; NAAS, I.A.; PEREIRA, D.F.; SALGADO, D.D. Estimativa do padrão de preferência térmica de matrizes pesadas (frango de corte). Revista Brasileira de Engenharia Agrícola e Ambiental, Campina Grande, v.11, n.2, p.211-216, 2007. Disponível em: <http://www.scielo.br/pdf/rbeaa/v11n2/v11n2a12.pdf > Acesso em: 12 mar. 2012. 
DAHLKE, F.; GONZÁLES, E.; GADELHA, A.C.; MAIORKA, A.; BORGES, S.A.; ROSA, P.S.; FILHO, D.E.F.; FURLAN, R.L. Empenamento, níveis hormonais de triiodotironina e tiroxina e temperatura corporal de frangos de corte de diferentes genótipos criados em diferentes condições de temperatura. Ciência Rural, Santa Maria, v.35, n.3, p.664-670, Mai/Jun, 2005a. Disponível em <http://www.scielo.br/pdf/cr/v35n3/a29v35n3.pdf > Acesso em: 12 mar. 2012.

DAHLKE, F.; GONZÁLES, E.; FURLAN, R.L.; GADELHA, A.C.; MAIORKA, A. FILHO, D.E.F.; ROSA, P.S. Efeito da temperatura ambiente sobre hormônios tireoideanos, temperatura corporal e empenamento de frangos de corte, fêmeas, de diferentes genótipos. Acta Scientiarum Animal Sciences, Maringá, v. 27, n. 3, p. 391-397, July/Sept., 2005b. Disponível em: $<$ http://www.periodicos.uem.br/ojs/index.php/ActaSciAnimSci/article/view/1216/648 > Acesso em: 12 mar 2012.

DAHLKE, F.; GONZÁLES, E.; FURLAN, R.L.; GADELHA, A.C.; ROSA, P.S.; MEURER, R.F.P.; MAIORKA, A. Desenvolvimento folicular de embriões de frangos de corte de diferentes genótipos expostos ao estresse térmico crônico.Ciência Rural, Santa Maria, v.38, n.8, p.2314-2320, 2008. Disponível em: <http://www.scielo.br/pdf/cr/v38n8/a34v38n8.pdf> Acesso em: 12 mar. 2012.

DIONELLO, N.J.L.; MACARI, M.; FERRO, J.A.; RUTZ, F.; FERRO, M.I.T.; FURLAN, L.R.; Respostas fisiológicas associadas à termotolerância em pintos de corte de duas linhagens por exposição a altas temperaturas, Revista Brasileira de Zootecnia, Viçosa, v.31, n.1, p.79-85, Jan-Fev, 2002.

FABRICIO, J.R. Influência do estresse calórico no rendimento da criação de frangos de corte. In: CONFERÊNCIA APINCO DE CIÊNCIA E TECNOLOGIA AVÍCOLAS, Santos, 1994. Anais... Campinas: FACTA, 1994. p.129-136.

FERREIRA, R.A. Maior produção com maior ambiente para aves, suínos e bovinos. Visçosa: Aprenda Fácil, 2005. 371p.

FURLAN, R.L. Influência da temperatura na produção de frangos de corte. In: SINPÓSIO BRASIL SUL DE AVICULTURA, 7., Chapecó, 2006. Anais... Chapecó, 2006. p.104-135.

GERAERT, P.A., PADILHA, J.C.F., GUILLAUMIN, S. Metabolic and endocrine changes induced by chronic heat exposure chickens: biological and endocrinological variables. British Journal of Nutrition, Edinburg, v.75, p.205-216, 1996.

GONZÁLEZ, F.H.D.; SILVA, S.C. Bioquímica Hormonal. In: GONZÁLEZ, F.H.D.; SILVA, S.C. Introdução à bioquímica clínica veterinária. 2. ed. Porto Alegre: UFRGS, p. 299-307, 2006.

GUYTON, A.C.; HALL, J.E. Tratado de Fisiologia Médica. In: Os hormônios metabólicos da tireóide. Tradução de Patrícia Lydie Voeux Pinho. Rio de Janeiro: Guanabara Koogan, 1997. p. 859-865.

LAGANÁ, C.; RIBEIRO, A.M.L.; GONZÁLEZ, F.H.D.; LACERDA, L.A.; KRATZ, L.R.; BARBOSA, P.R. Níveis dietéticos de proteína e gordura e parâmetros bioquímicos, hematológicos e empenamento em frangos de corte estressados pelo calor. Revista Brasileira de Zootecnia, Viçosa, v.36, n.6, p.1783-1790, 2007.

LUTAIF, N.A.; GONTIJO, J.A.R. Contribuição Renal para a Termoregulação: Termogênese e a Doença Renal. Jornal Brasileiro de Nefrologia, São Paulo. v.31, n.1, p.62-69, 2009. 
MARCHINI, C.F.P.; SILVA, P.L.; NASCIMENTO, M.R.B.M; TAVARES, M. Frequência respiratória e temperatura cloacal em frangos de corte submetidos à temperatura ambiente cíclica elevada.

Archives of Veterinary Science, Curitiba, v.12, n.1, p.41-46, 2007. Disponível em:

<http://calvados.c3sl.ufpr.br/ojs2/index.php/veterinary/article/view/9227 > Acesso em: 12 mar. 2012.

MARTINEZ, J.E.P. Ácido ascórbico estabilizado com flavonóides cítricos para frangos de corte sob estresse calórico: Efeitos no desempenho e qualidade da carne. 2008. 80f. Dissertação de Mestrado em Zootecnia- Faculdade de Agronomia, Universidade Federal do Rio Grande do Sul, Porto Alegre, 2008.

MARTINEZ, J.E.P. Ácido ascórbico estabilizado com flavonóides cítricos para frangos de corte sob estresse calórico: efeitos no desempenho e qualidade da carne. Lume, Rio Grande do Sul. 80p. 2008. Disponível em: <http://hdl.handle.net/10183/15731> Acesso em: 12 mar. 2012.

MAZZI, C.M; FERRO, M.I.T.; COELHO, A.A.D.; SAVINO, V.J.M.; MACARI, M.; FERRO, J.A.; GIVISIEZ, P.E.N.; GIACHETTO, P.F.; SILVA, M.M.; DIONELLO, N.J.L. Effect of heat exposure on the thermoregulatory responses of selected naked neck chickens. Arquivo Brasileiro de Medicina Veterinária e Zootecnia, Belo horizonte, v. 54, n. 1, Fev, 2002. Disponível em: $<$ http://www.scielo.br/scielo.php?pid=S010209352002000100006\&script=sci arttext\&tlng=pt > Acesso em: 11 mar. 2012.

MEDEIROS, C.M.; BAÊTA, F.C.; OLIVEIRA, R.F.M.; TINÔCO, I.F.F.; ALBINO, L.F.T.; CECON, P.R. Efeitos da temperatura, umidade relativa e velocidade do ar em frangos de corte. Revista Engenharia na Agricultura, Viçosa, v.13, n.4, p. 277-286, Out./Dez., 2005. Disponível em: <http://www.ufv.br/dea/reveng/arquivos/Vol13/v13n4p277-286.pdf > Acesso em: 11 mar. 2012.

MENEGALI, I.; TINÔCO, I.F.F.; BAÊTA, F.C.; CECON, P.R.; GUIMARÃES, M.C.C.; CORDEIRO, M.B. Ambiente térmico e concentração de gases em instalações para frangos de corte no período de aquecimento. Revista Brasileira de Engenharia Agrícola e Ambiental, Campina Grande, v. 13, (Suplemento), p.984-990, 2009. Disponível em:

<http://www.scielo.br/pdf/rbeaa/v13s0/v13s0a22.pdf > Acesso em: 11 mar. 2012.

MOURA, D.J. Ambiência na avicultura de corte. In: SILVA, I.J.O. Ambiência na produção de aves em clima tropical. Piracicaba: FUNEP, p.81-93, 2001.

NAZARENO, A.C.; PANDORFI, H.; ALMEIDA, G.L.P.; GIONGO, P.R.; PEDROSA, E.M.R.; GUISELINI, C. Avaliação do conforto térmico e desempenho de frangos de corte sob regime de criação

diferenciado. Revista Brasileira de Engenharia Agrícola e Ambiental, Campina Grande, v.13, n.6, p.802-808, 2009. Disponível em: <http://www.scielo.br/pdf/rbeaa/v13n6/v13n6a20.pdf > Acesso em: 11 mar. 2012.

NAZARENO, A.C.; PANDORFI, H.; GUISELINI, C.; VIGODERIS, R.B.; PEDROSA, E.M.R. Bem-estar na produção de frangos de corte em diferentes sistemas de criação. Engenharia Agrícola, Jaboticabal, v.31, n.1, p.13-22, Jan./Fev., 2011. Disponível em:

<http://www.scielo.br/pdf/eagri/v31n1/v31n1a02.pdf > Acesso em: 11 mar. 2012. 
OLIVEIRA, R.F.M.; ZANUSSO, J.T.; DONZELE, J.L.; FERREIRA, R.A.; ALBINO, L.F.T.; VALERIO, S.R.; NETO, A.R.O.; CARMO, H.M. Níveis de energia metabolizavel para frangos de corte de 1 a 21 dias de idade mantidos em ambiente de alta temperatura. Revista Brasileira de Zootecnia, Viçosa, v. 29, n. 3, p. 810-816, 2000. Disponível em:

$<$ http://www.scielo.br/scielo.php?script=sci arttext\&pid=S1516-35982000000300024 > Acesso em: 11 mar. 2012.

OLIVEIRA, R.F.M.; DONZELE, J.L.; ABREU, M.L.T.; FERREIRA, R.A.; VAZA, R.G.M.V.; CELLA, P.S. Efeitos da temperatura e da umidade relativa sobre o desempenho e o rendimento de cortes nobres de frangos de corte de 1 a 49 dias de idade. Revista Brasileira de Zootecnia, Viçosa, v.35, n.3, p.797-803, 2006. Disponível em: < http://www.scielo.br/pdf/rbz/v35n3/30072.pdf > Acesso em: 11 março de 2011.

OLIVEIRA NETO, R. A.; OLIVEIRA, M. F. R.; DONZELE, J. L.; Metabolizable energy level for broilers from 22 to 42 days of age maintained under thermoneutral environment. Revista Brasileira de Zootecnia, Viçosa, v.29, n.4, p. 1132-1140, 2000.

PLAVNIK, I.; HURWITZ, S. The performance of broiler chicks during and following a severe feed restriction at an early age. Poultry Science, Champaign, v.64, n.2, p.348-355, 1985.

PLAVNIK, I.; YAHAV, S. Effect of environmental temperature on broiler chickens subjected to growth restriction at an early age. Poultry Science, Champaign, v.77, n.6, p.870-872, 1998.

RIBEIRO, A. M. L.; PENZ, A.M.; TEETER, R. Effects of 2-hydroxy-4-(methylthio)butanoic acid and DL-Methionine on broiler performance and compensatory growth after exposure to two different environmental temperatures. Journal of Applied Poultry Research, Athens, v.10, n.4, p.419426, 2001.

RODRIGUEZ, E. Fisiologia da homeotermia In: Conforto térmico das construções. 2002. Disponível em: <www.ufrrj.br/institutos/it/dau/profs/edmundo/Cap\%EDtulo3-Homeotermia.pdf> . Acesso em: 30 abr. 2012.

SEVEGNANI, K.B.; CARO, I.W.; PANDORFI, H.; SILVA, I.J.O.; MOURAS, D.J. Zootecnia de precisão: análise de imagens no estudo do comportamento de frangos de corte em estresse térmico. Revista Brasileira de Engenharia Agrícola e Ambiental, Campina Grande, v. 9, n.1, p.115-119, 2005. Disponível em: <http://www.scielo.br/pdf/rbeaa/v9n1/v9n1a17.pdf>. Acesso em: 11 mar. 2012.

SILVA, R.G. Introdução a Bioclimatologia animal. São Paulo: Nobel, 2000. 283p.

SOUZA, L.F.A. Exposição crônica e cíclica ao calor em frangos de corte: desempenho, metabolização dos nutrientes e atividade de enzimas pancreáticas. 2008. 62f. Dissertação (Mestrado em Zootecnia) - Faculdade de

Ciências Agrárias e Veterinárias da Universidade Estadual Paulista "Júlio de Mesquita Filho", Jaboticabal, 2008.

TINÔCO, I. F. F. Ambiência e instalações para a avicultura industrial.In: Congresso Brasileiro de Engenharia Agrícola, 27, e Encontro Nacional de Técnicos, Pesquisadores e Educadores de Construções Rurais, 3, Poços de Caldas, Anais... Lavras: UFLA/SBEA, 1998: p.1-86. 
WELKER, J.S.; ROSA, A.P.; MOURA, D.J.; MACHADO, L.P.; CATELAN, F.; UTTPATEL, R.

Temperatura corporal de frangos de corte em diferentes sistemas de climatização. Revista

Brasileira de Zootecnia, Viçosa, v.37, n.8, p.1463-1467, 2008. Disponível em

<http://www.scielo.br/pdf/rbz/v37n8/v37n8a18.pdf> Acesso em: 13 mar. 2012. 